\title{
IMPORTÂNCIA DO METABOLISMO NO PLANEJAMENTO DE FÁRMACOS
}

\author{
Dárcio Gomes Pereira* \\ Galeno Research Unit, R. Latino Coelho, 1301, 13087-010 Campinas - SP, Brasil
}

Recebido em 11/7/05; aceito em 10/2/06; publicado na web em 30/8/06

\begin{abstract}
THE IMPORTANCE OF METABOLISM IN DRUG DESIGN. It is widely recognized that pharmacokinetic optimization needs to be addressed early in drug discovery to reduce the high failure rate in bringing drugs to market. Poor absorption, too short duration of action due to high elimination rate, or the presence of active metabolites are examples of properties that can potentially lead to unsuccessful clinical programmes. Here I describe a brief overview of advantages and molecular strategies for improving metabolic and pharmacokinetic properties applied to the discovery of fluconazol, $\beta$-blockers, ritonavir and ezetimibe and to the development of the prodrugs enalapril and bambuterol.
\end{abstract}

Keywords: drug metabolism; drug design; structure-metabolism relationship.

\section{INTRODUÇÃO}

A ação de um fármaco, quando administrado a humanos ou animais, pode ser dividida em três fases: fase farmacêutica, fase farmacocinética e fase farmacodinâmica ${ }^{1}$ (Esquema 1). Na fase farmacêutica, ocorre a desintegração da forma de dosagem, seguida da dissolução da substância ativa. A fase farmacocinética abrange os processos de absorção, distribuição, metabolismo e excreção (ADME), ou seja, "o que o organismo faz com o fármaco". A fase farmacodinâmica está relacionada com a interação do fármaco com seu alvo (receptor, enzimas etc.) e a conseqüente produção do efeito terapêutico, e pode ser entendida como "o que o fármaco faz no organismo",

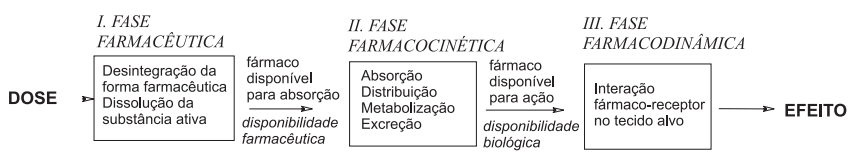

Esquema 1. Fases importantes da ação de fármacos

Nota-se que a fase farmacocinética pode ter profundo impacto sobre o efeito farmacológico, uma vez que os processos de ADME determinam a concentração e o tempo despendido das moléculas do fármaco no seu local de ação ${ }^{2}$.

Tradicionalmente, a pesquisa de fármacos concentra seus esforços iniciais na fase farmacodinâmica. Triagens preliminares usam modelos in vitro, tais como enzimas, receptores ou tecidos, para obter a relação entre os novos compostos e sua potência agonista ou antagonista. A partir destes estudos, triagens secundárias e terciárias freqüentemente são dirigidas à administração do composto a animais, por via oral ou intravenosa, com observação do efeito farmacológico ${ }^{3}$. Entretanto, muitos dos compostos que se mostram promissores nos testes in vitro não apresentam boa atividade em animais ${ }^{4}$. Esta falha de correlação, muitas vezes associada a problemas farmacocinéticos dos compostos, como baixa biodisponibilidade, duração de ação (muito curta ou muito longa), ou a presença de metabólitos ativos, pode levar a programas clínicos mal-sucedidos. Para ilustrar, Prentis e colaboradores ${ }^{5}$ relata-

*e-mail: darcio@sigmanet.com.br ram que, entre o período de 1964 a 1985, sete companhias farmacêuticas estabelecidas no Reino Unido introduziram 49 novas entidades químicas no mercado, enquanto 198 compostos foram abandonados no desenvolvimento. A principal razão para o término foi farmacocinética inapropriada $(39,4 \%)$.

No processo de descoberta de novos medicamentos, a previsão dos processos de ADME logo nos estágios iniciais da pesquisa é de extrema importância ${ }^{6}$. A otimização destas propriedades, através de modificações moleculares de compostos promissores, é essencial na seleção de compostos candidatos com maiores probabilidades de não serem abandonados, mais adiante, na fase clínica. $\mathrm{O}$ fracasso na fase clínica representa grandes perdas de tempo e dinheiro ${ }^{7}$.

Dentre as estratégias de modificação molecular, a preparação de pró-fármacos - também chamada de latenciação de fármacos ${ }^{8}$ - tem recebido especial atenção. O termo pró-fármaco foi introduzido por Albert, em 1958, para descrever compostos que necessitam de biotransformação prévia para promover efeito farmacológico ${ }^{9}$. Consiste essencialmente em converter, mediante modificação química, um composto biologicamente ativo em forma de transporte inativa que, após sofrer ataque enzimático ou químico, libertará o fármaco ativo ${ }^{8}$. Diversas barreiras que limitam o uso de um fármaco podem ser superadas, tais como baixa solubilidade, sabor ou odor inaceitáveis, irritação ou dor no local de aplicação, inadequada permeabilidade pela barreira hemato-encefálica, baixa biodisponibilidade e extenso metabolismo pré-sistêmico. Estas duas últimas propriedades serão discutidas, mais adiante, no contexto da descoberta do enalapril e do bambuterol.

\section{IMPORTÂNCIA DO ESTUDO DE METABOLISMO}

O metabolismo de fármacos compreende o conjunto de reações enzimáticas que biotransformam fármacos e outros compostos estranhos (xenobióticos) em metabólitos de polaridade crescente, para que sejam excretados pela urina ${ }^{10}$. O metabolismo desempenha, assim, um importante papel na eliminação de fármacos, e impede que estes compostos permaneçam por tempo indefinido no nosso organismo ${ }^{11}$.

As reações metabólicas são divididas em fase 1 (oxidação, redução e hidrólise) e fase 2 (conjugação). Os produtos de degradação (metabólitos), por sua vez, podem ser inativos ou ativos. Em 
relação ao fármaco de origem, os metabólitos ativos podem agir por mecanismos de ação similares ou diferentes, ou até mesmo por antagonismo. O conhecimento da cinética da formação dos metabólitos ativos é importante não apenas para previsão do resultado terapêutico, mas também para explicar a toxicidade de um dado fármaco ${ }^{12}$.

Podemos imaginar que, durante o curso de um tratamento, uma variedade de metabólitos circulantes, ativos ou inativos, bioformados em diferentes quantidades e velocidades relativas, estará presente em indivíduos que fazem uso de medicamentos. Fica claro que a capacidade metabólica de cada indivíduo influencia grandemente esta complexa cinética e pode resultar em diferentes respostas terapêuticas. Além disso, o uso crônico de medicamentos pode induzir alterações da função hepática de determinado paciente, resultando em indução enzimática, em que a atividade metabólica se torna exacerbada, ou, contrariamente, de inibição da função enzimática hepática ${ }^{10}$.

Como o fígado é o principal órgão metabolizador (incluindo a geração de metabólitos ativos ou tóxicos, depuração, interações farmacológicas e variabilidade individual), a depuração hepática é o principal alvo da otimização da farmacocinética de uma série de $\operatorname{compostos}^{13}$. O bloqueio, ou mesmo a promoção do metabolismo, podem ser manipulados no sentido de obter fármacos com perfis farmacológicos mais favoráveis. Como veremos adiante, diversas vantagens surgem destas abordagens. A redução do número de metabólitos ativos, por ex., favorece uma cinética mais previsível e reduz a variabilidade individual, na medida em que a depuração metabólica dá lugar à depuração renal.

\section{Vantagens do aumento da estabilidade metabólica}

Várias vantagens estão associadas com o aumento da estabilidade metabólica ${ }^{14,15}$ : aumento da biodisponibilidade e maior $\mathrm{t}_{1 / 2}$ que, por sua vez podem permitir doses menores e menos freqüentes, proporcionando melhor adesão do paciente; melhor congruência entre dose e concentração plasmática, conseqüentemente reduzindo ou mesmo eliminando a necessidade de caros monitoramentos terapêuticos; menores diferenças no metabolismo entre espécies, o que pode permitir a melhor extrapolação dos dados de animais para humanos; menor variabilidade inter- e intra-paciente nos níveis plasmáticos; redução do número e significância de metabólitos ativos e conseqüente redução da necessidade de estudos adicionais de metabólitos em animais e humanos.

\section{Estratégias para aumentar a estabilidade metabólica}

De modo geral, o metabolismo pode ser reduzido através da incorporação de grupos funcionais estáveis (ex. grupos bloqueadores) em sítios metabolicamente vulneráveis, desde que estas mudanças não sejam prejudiciais à atividade farmacológica. Exemplos clássi$\cos$ incluem ${ }^{14-16}$ : bloqueio da oxidação de posições específicas em anéis aromáticos através da introdução de grupos fortemente retiradores de elétrons (ex. $-\mathrm{CF}_{3},-\mathrm{SO}_{2} \mathrm{NH}_{2},-\mathrm{SO}_{3}^{-}$); introdução de um grupo $N$-t-butil para prevenir a $N$-desalquilação; troca de uma ligação éster lábil por um grupo amida; restringir a molécula em uma conformação desfavorável para a via metabólica, mais comumente através do bloqueio de um grupo lábil por impedimento estérico. A função fenólica é rapidamente inativada por conjugação no intestino e no fígado ${ }^{17}$. Portanto, sugere-se evitar este grupo em posições estericamente desprotegidas para qualquer composto destinado para uso oral. Deve-se considerar, entretanto, que o aumento da estabilidade metabólica pode trazer desvantagens, como longos tempos de meia-vida e riscos de acúmulo do fármaco.
Outra estratégia que pode melhorar a estabilidade metabólica é a redução da lipofilicidade $(\log \mathrm{P}, \log \mathrm{D})$ da estrutura. Isto se deve ao fato de que as enzimas metabolizadoras geralmente apresentam um sítio de ligação lipofílico e, portanto, aceitam moléculas lipofílicas ${ }^{13}$.

Uma variedade de métodos pode ser usada para reduzir a lipofilicidade de uma molécula. A simples remoção ou redução de grupos lipofílicos, ou ainda a introdução de grupos ou átomos isósteros mais polares, são exemplos. Vale mencionar, entretanto, que tais intervenções nem sempre são bem-sucedidas, uma vez que grupos lipofílicos estão geralmente envolvidos na ligação com o alvo terapêutico e podem, portanto, prejudicar a potência do composto $^{13}$. Além disso, a introdução de certos grupos polares pode, em alguns casos, favorecer reações de metabolização.

Nas sessões seguintes, algumas estratégias usadas para bloquear, ou mesmo favorecer o metabolismo, são discutidas no contexto da descoberta do fluconazol, dos $\beta$-bloqueadores, do ritonavir, da ezetimiba e no desenvolvimento dos pró-fármacos enalapril e bambuterol.

\section{A descoberta do antifúngico fluconazol}

A descoberta do fluconazol foi resultado de um programa de pesquisa dirigido ao desenvolvimento de um agente antifúngico de amplo espectro de ação, ativo pelas vias oral e intravenosa, para tratamento de infecções superficiais e sistêmicas ${ }^{18}$.

Os derivados imidazólicos foram escolhidos como materiais de partida porque eram geralmente bem tolerados e, também, porque ofereciam a vantagem de um modo de ação seletivo - a inibição de uma enzima crucial na biossíntese do ergosterol da membrana de fungos: a C-14 desmetilase ${ }^{20}$. Quando administrados por via oral, entretanto, estes compostos (ex. 1 e 2) sofriam extenso metabolismo de primeira-passagem no fígado, o que conseqüentemente resultava em baixa biodisponibilidade. Além disso, a alta lipofilicidade de muitos deles levava a um alto grau de ligação às proteínas plasmáticas (frequentemente $>99 \%$ ) e, assim, à presença de baixos níveis do fármaco não-ligado no sítio da infecção. $\mathrm{O}$ cetoconazol (3), particularmente, foi o primeiro antifúngico imidazólico ativo por via oral e, embora ainda susceptível à degradação metabólica, foi menos vulnerável que os primeiros derivados da classe $\mathrm{e}^{18}$. A biodisponibilidade do cetoconazol (3) é variável devida, pelo menos em parte, à sua baixa solubilidade em água ${ }^{21}$.

A procura por antifúngicos com farmacocinética aceitável e metabolicamente estáveis levou à descoberta da série de compostos bis-triazólicos. O composto (4), particularmente, embora com notável atividade em camundongos infectados por Candida, por sua alta lipoficilidade $(\log \mathrm{P}$ octanol $=1,5)$ e baixa taxa de metabolismo resultou em cinética não-linear e níveis sanguíneos prolongados ${ }^{22}$. $\mathrm{O}$ fluconazol (5) foi o mais polar $(\log \mathrm{P}$ octanol $=0,5)$ da série e, devido à sua adequada solubilidade em água $\left(8 \mathrm{mg} / \mathrm{mL}\right.$ a $\left.37^{\circ} \mathrm{C}\right)$, pode ser prontamente formulado para uso intravenoso (Tabela 1). Embora o fluconazol (5) apresente lipofilicidade suficiente para ser consideravelmente reabsorvido (80\%) no túbulo renal, sua depuração é predominantemente renal devido à sua alta estabilidade metabólica. A sua baixa taxa de depuração renal proporciona um tempo de meia-vida de $30 \mathrm{~h}$, adequado para administração uma vez ao dia ${ }^{21}$. A estabilidade metabólica do fluconazol (5) foi conseguida pela combinação de três elementos estruturais: a resistência dos anéis triazólicos ao ataque oxidativo; o bloqueio da hidroxilação aromática pela presença dos dois átomos de flúor e o impedimento estérico da hidroxila, um sítio de possível conjugação ${ }^{23}$.

Em suma, após anos de modificações moleculares sistematicamente planejadas, o fluconazol (5) surgiu como um promissor 
<smiles>CCCCCCC(O)(Cn1ccnc1)c1ccc(Cl)cc1Cl</smiles>

Figura 1. Estruturas químicas dos antifúngicos inibidores da C-14 desmetilase

Tabela 1. Dados de farmacocinética e de solubilidade de dois potentes derivados bis-triazólicos em cães<smiles>[R2]c1ccc(C(O)(Cn2cncn2)Cn2cncn2)c([R])c1</smiles>

\begin{tabular}{llc}
\hline Parâmetro & $(\mathbf{4})$ & Fluconazol (5) \\
\hline $\mathrm{R}_{1}$ & $\mathrm{Cl}$ & $\mathrm{F}$ \\
$\mathrm{R}_{2}$ & $\mathrm{Cl}$ & $\mathrm{F}$ \\
Log P & 1,5 & 0,5 \\
Ligação à proteína plasmática (\%) & 43 & 11 \\
$\begin{array}{l}\text { Depuração renal (não-metabolizado) } \\
\text { (mL/min por kg) }\end{array}$ & 0,05 & 0,46 \\
$\begin{array}{l}\text { Depuração não-renal (mL/min por kg) } \\
\text { Solubilidade em água (mg/mL) }\end{array}$ & 0,45 & $0,19^{*}$ \\
\hline
\end{tabular}

* Principalmente excreção na forma inalterada nas fezes.

antifúngico graças à ótima combinação de eficácia, características farmacocinéticas, solubilidade em água e perfil de segurança.

\section{A descoberta dos $\beta$-bloqueadores}

A descoberta dos antagonistas $\beta$ adrenérgicos é um exemplo de como a busca de estabilidade metabólica pode ser associada com melhoria da seletividade farmacológica. O propranolol (6) foi o primeiro antagonista puro da classe e suas ações resultam do bloqueio dos receptores $\beta_{1}$ e $\beta_{2}$ com igual afinidade. É usado no tratamento de hipertensão, angina pectoris e arritmias cardíacas. Duas desvantagens clinicamente relevantes do propranolol (6) incluem sua contra-indicação na asma e na bronquite, devida ao bloqueio $\beta_{2} \mathrm{e}$ seu extenso metabolismo de primeira passagem pelo fígado, que resulta em baixa biodisponibilidade oral (cerca de 25\%). Estas limitações impulsionaram a pesquisa de novos antagonistas cardiosseletivos, com baixo metabolismo de primeira-passagem, com maior tempo de ação e livres de metabólitos ativos ${ }^{25}$.

Estudos de relação estrutura-atividade para esta classe indicaram que a natureza do anel aromático, bem como a dos substituintes na posição para do anel, eram determinantes na seletividade $\beta_{1} \mathrm{e}$ também afetavam a absorção, a excreção e o metabolismo dos $\beta$ bloqueadores $^{26}$ (Figura 2). Modificações nesta subunidade estrutural levaram à descoberta de importantes antagonistas $\beta_{1}$ cardiosseletivos, como metoprolol (7), betaxolol (8) e esmolol (9).

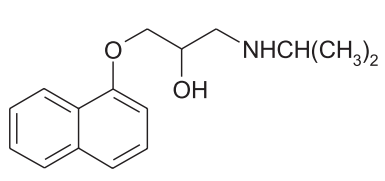

(6) propranolol<smiles>CCNCC(O)COc1ccc(COCC)cc1</smiles>

(8) betaxolol

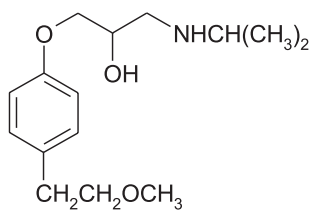

(7) metoprolol

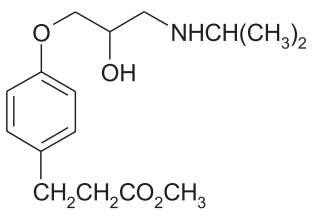

(9) esmolol
Figura 2. Estruturas químicas dos $\beta$-bloqueadores ${ }^{2}$

Apesar do metoprolol (7) apresentar maior afinidade pelos receptores $\beta_{1}$, observou-se que o substituinte metoxietila presente na posição para do anel era alvo de extenso metabolismo hepático (Figura 2). Isto explica, em grande parte, sua baixa biodisponibilidade (cerca de 50\%) e seu curto tempo de ação (3-5 h) $)^{21}$ (Tabela 2).

Neste sentido, o betaxolol (8) foi planejado partindo-se da hipótese de que a introdução de substituintes volumosos e estáveis na posição para poderiam gerar fármacos resistentes ao metabolismo e ainda cardiosseletivos ${ }^{25}$. A combinação destas características foi conseguida com o grupo ciclopropila que, particularmente, foi muito mais estável à retirada de hidrogênio que outros grupos alquilas, ao mesmo tempo em que proporcionou uma alta potência antagonista $\beta_{1}{ }^{21}$. As vantagens farmacocinéticas do betaxolol (8) sobre o metoprolol (7) podem ser observadas por sua maior biodisponibilidade oral (80 contra 50\%) e por seu maior tempo de meia-vida (14-22 contra 3-5 h) (Tabela 2).

Por outro lado, o esmolol (9) foi planejado para ter um tempo de ação propositalmente muito curto (em torno de $8 \mathrm{~min}$ ). O seu breve tempo de ação é resultado da rápida hidrólise de sua função éster por esterases presentes nos eritrócitos ${ }^{27}$. O metabólito ácido

Tabela 2. Dados de farmacocinética de alguns $\beta$-bloqueadores em humanos

\begin{tabular}{lccc}
\hline Fármaco & Log P (octanol/água $)^{24}$ & biodisponibilidade oral (em \%) & tempo de meia-vida (em h) \\
\hline Propranolol & 3,65 & Cerca de 25 & $3-5$ \\
Metoprolol & 2,15 & Cerca de 40 & $3-4$ \\
Betaxolol & 2,81 & Cerca de $80^{19}$ & $14-22^{19}$ \\
Esmolol & - & - & 0,13 \\
\hline
\end{tabular}


formado, embora apresente um tempo de meia-vida relativamente longo ( 3 a 4 h), é muito menos ativo que o esmolol (9) ${ }^{28}$. O esmolol (9) é administrado por infusão intravenosa quando se deseja um bloqueio $\beta$ de curta duração ou em pacientes gravemente enfermos, nos quais os efeitos adversos de bradicardia, insuficiência cardíaca ou hipotensão podem exigir rápida suspensão do fármaco ${ }^{29}$.

A promoção metabólica, aplicada na descoberta do esmolol (9), enquadra-se no planejamento de fármacos "moles" ("soft drugs"). Fármacos "moles" são definidos como "compostos biologicamente ativos (fármacos) caracterizados por um previsível metabolismo in vivo a espécies não-tóxicas, após eles terem alcançado suas funções terapêuticas" ${ }^{30}$.

Fármacos "duros" ("hard drugs"), por outro lado, são compostos planejados para conter as características estruturais necessárias para a atividade farmacológica, mas em uma forma não susceptível à transformação metabólica ou química ${ }^{31}$. O planejamento de fármacos "duros" é bastante atraente, não apenas porque soluciona o problema de toxicidade devido a intermediários reativos ou metabólitos ativos, mas também porque proporciona uma farmacocinética mais simples e previsível, de modo que o fármaco seja excretado primariamente pela bile ou pelos rins ${ }^{32}$. Neste caso, a variabilidade inter-individual, em grande parte devida a diferenças na capacidade metabólica, é evitada.

\section{A descoberta do ritonavir}

O planejamento do ritonavir (10) resultou de intensos esforços na procura de um novo inibidor de protease de HIV, com potência antiviral e propriedades farmacocinéticas ótimas.

Em 1994, pesquisadores da Abbott identificaram o composto A-80987 (11) que, embora com boa potência inibidora de protease e moderada biodisponibilidade oral, apresentava tempo de meiavida curto, uma limitação comum a muitos peptidomiméticos ${ }^{33}$. Após a observação de que este composto era metabolizado e eliminado primariamente através de $N$-oxidação dos grupos piridinas, os esforços concentraram-se na tentativa de reduzir a taxa de metabolismo, combinada com melhor atividade anti-HIV ${ }^{34}$.
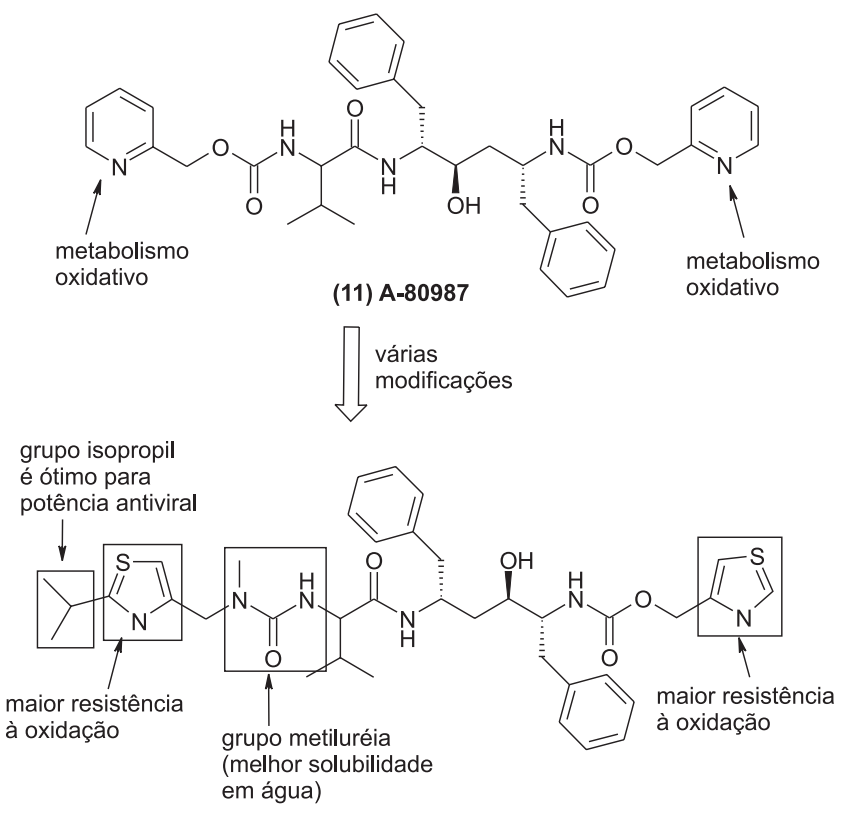

(10) ritonavir

Figura 3. Estruturas químicas dos inibidores de proteases do HIV
A estratégia baseou-se na hipótese de que a redução do metabolismo poderia não apenas melhorar a biodisponibilidade oral, mas também aumentar o tempo de meia-vida. Como resultado, a obtenção de altos níveis plasmáticos prolongados poderia produzir um efeito antiviral mais intenso, bem como retardar a emergência de mutantes resistentes, graças à supressão mais efetiva ${ }^{34}$ da replicação viral.

A substituição dos grupos piridinas presentes no composto A80987 (11) por heterociclos altamente deficientes de elétrons, particularmente oxazóis e tiazóis, levou a reduções substanciais na degradação metabólica e na excreção dos inibidores. A presença do grupo tiazólico combinou melhor potência e perfil farmacocinético, porém, a baixa solubilidade em água deste anel limitava a absorção intestinal e prejudicava a formulação injetável para alguns compostos. Neste sentido, a modificação do grupo carbamato para o ligante mais solúvel $N$-metiluréia proporcionou melhor biodisponibilidade oral, como foi o caso do ritonavir (10). A unidade isopropiltiazolil presente no ritonavir (10) contribui para maior potência em relação ao composto A-80987 (11), e parece estar relacionada com interações hidrofóbicas com o resíduo de valina-82 da protease do HIV. A substituição do grupo isopropil por outros (ex., metil, etil, t-butil) revelou-se prejudicial para a atividade ${ }^{34}$.

O ritonavir (10) foi o primeiro inibidor de protease do HIV a trazer benefício na sobrevida dos pacientes ${ }^{35}$. Está disponível na clínica como fármaco isolado, ou em associação com lopinavir, para tratamento da infecção por HIV em adultos e crianças.

\section{A descoberta da ezetimiba}

A descoberta do inibidor da absorção de colesterol ezetimiba (12) $\left(\right.$ Zetia $\left.^{\circledR}\right)$, por pesquisadores da Schering-Plough, representa outro notável exemplo da aplicação dos conceitos de metabolismo no planejamento de fármacos.

Dentre vários compostos inicialmente testados, o protótipo SCH-48461 (13) foi identificado como inibidor da absorção luminal do colesterol, levando a uma redução dose-dependente do colesterol total e dos níveis de éster colesteril hepático em ratos, macacos e humanos ${ }^{14}$. Estudos revelaram, porém, que estes efeitos eram devidos, em grande parte, à presença de um metabólito glicuronídeo deste composto. Após sofrer desmetilação, o metabólito fenólico de SCH-48461 (13) formado era, então, conjugado com ácido glicurônico. Além de ativo, este metabólito se concentrava na luz e na parede do intestino, justamente nos possíveis locais de ação. Este metabolismo "produtivo" justificou, portanto, a substituição do grupo metoxila pela hidroxila fenólica, pois promovia uma conjugação direta com ácido glicurônico. De maneira similar, o composto $(S)$-hidroxilado, possível metabólito formado pela oxidação do carbono benzílico, revelou-se também mais ativo que o protótipo. Assim, a introdução das hidroxilas fenólica e benzílica foi muito favorável para a potência farmacológica, especialmente em macacos, nos quais a ezetimiba foi 4.000 vezes mais ativa que o protótipo $\left(\mathrm{DE}_{50}=2,0 \text { e } 0,0005 \mathrm{mg} / \mathrm{kg} \text {, respectivamente }\right)^{36}$.

Por outro lado, a hidroxilação da posição para da cadeia fenilpropílica, bem como a desmetilação na posição $N$-arila, geravam compostos menos ativos, eventuais metabólitos que poderiam comprometer o efeito. Neste sentido, a substituição do átomo de hidrogênio e do grupo metoxila, presentes no protótipo, por um átomo de flúor tornou estas posições resistentes ao ataque oxidativo e, conseqüentemente, contribuiu para evitar a inativação da molécula ${ }^{36}$.

Aprovada pelo FDA em 2002 para redução dos níveis de colesterol em pacientes com hipercolesterolemia, a ezetimiba (12) é usada em associação com sinvastatina (um inibidor da enzima HMGCoA redutase) ou isoladamente, na dose de $10 \mathrm{mg}^{37}$. 


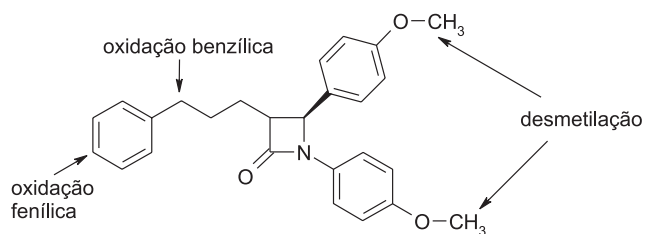

(13) SCH-48461

$$
\begin{aligned}
& \text { Otimização do } \\
& \text { metabolismo } \\
& \text { dirigida pela R.E.A. }
\end{aligned}
$$

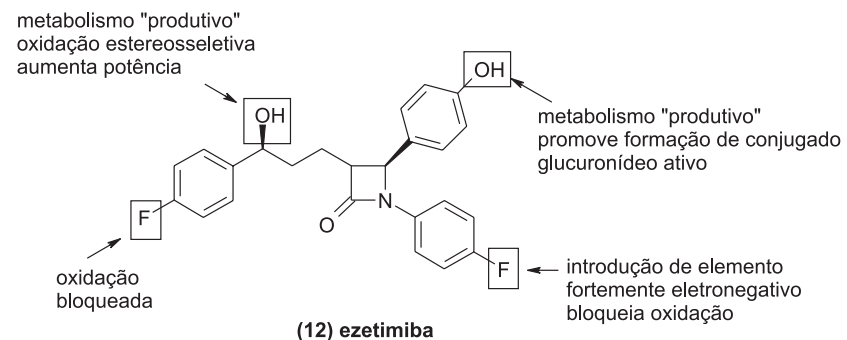

(12) ezetimiba bloqueia oxidação

\begin{tabular}{|lccc|}
\hline$\underline{D E}_{\underline{50}}:$ & (12) $\mathrm{SCH}-48461$ & & (13) ezetimiba \\
Hamster: & $2,2 \mathrm{mg} / \mathrm{kg}$ & & $0,04 \mathrm{mg} / \mathrm{kg}$ \\
Rato: & $2,0 \mathrm{mg} / \mathrm{kg}$ & $0,03 \mathrm{mg} / \mathrm{kg}$ \\
Macaco: & $0,2 \mathrm{mg} / \mathrm{kg}$ & $0,0005 \mathrm{mg} / \mathrm{kg}$ \\
Cão: & $0,1 \mathrm{mg} / \mathrm{kg}$ & $0,007 \mathrm{mg} / \mathrm{kg}$ \\
\hline
\end{tabular}

Figura 4. Estruturas químicas dos inibidores de absorção de colesterol

\section{O desenvolvimento dos pró-fármacos enalapril e bambuterol}

Pró-fármacos podem ser definidos como "agentes terapêuticos que são inativos per se, mas que são previsivelmente transformados em metabólitos ativos" ${ }^{38}$. Neste sentido, pró-fármacos são o contrário de fármacos "moles", já que estes últimos são, a princípio, ativos, e dão origem a metabólitos inativos.

O planejamento de pró-fármacos é de grande importância para a superação de problemas de ordens farmacêutica e farmacocinética relacionados ao fármaco que, de outra forma, poderiam limitar sua utilidade clínica ${ }^{17}$. Os principais objetivos do planejamento de prófármacos são $\mathrm{O}^{15,39,40}$ : melhorar a formulação (p. ex., aumentar a hidrossolubilidade); melhorar a estabilidade química; melhorar a aceitação e adesão do paciente; melhorar a biodisponibilidade; prolongar a duração de ação; melhorar a seletividade e, reduzir os efeitos colaterais.

O grande sucesso da preparação de pró-fármacos está bem documentado na literatura ${ }^{41}$ e pode ser demonstrado por muitos exemplos de melhoria da biodisponibilidade de fármacos destinados à administração oral, retal, ocular ou dérmica. Baixa absorção e/ou extenso metabolismo pré-sistêmico (de primeira passagem) são fatores que limitam a biodisponibilidade, e serão discutidos adiante.

Um balanço adequado entre solubilidade em água e lipofilicidade é de fundamental importância para a absorção passiva de fármacos. Fármacos muito polares ou hidrofílicos tendem a apresentar baixa biodisponibilidade, em virtude de suas baixas permeabilidades pelas membranas celulares, que são de natureza lipoprotéica. Baixa absorção também é freqüentemente observada para fármacos muito apolares ou lipofílicos, como resultado da baixa solubilidade em água e das características de dissolução destes compostos no meio biológico ${ }^{17}$.

Neste sentido, a conversão de um fármaco na sua forma de transporte inativa (pró-fármaco) pode melhorar suas propriedades

físico-químicas, de modo a superar estas limitações. Muitas vezes, isto é feito através da introdução de unidades de transporte temporárias - mais hidrofílicas ou mais lipofílicas, dependendo do objetivo - na molécula do fármaco. Exemplo clássico é o planejamento do enalapril (14) a partir ácido enalaprílico (15).

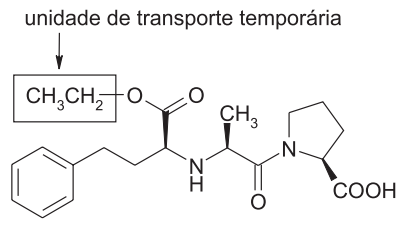

(14) enalapril

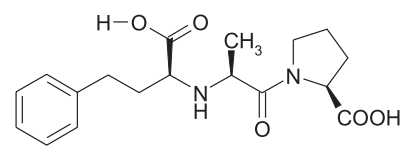

(15) ácido enalaprílico $\log \mathrm{P}$ (octanol/água; exp.) $=2,45$

Figura 5. Estruturas químicas dos anti-hipertensivos inibidores da enzima conversora de angiotensina

À época de sua descoberta, o ácido enalaprílico (15) revelouse com excelente atividade anti-hipertensiva, particularmente como inibidor da enzima conversora de angiotensina ${ }^{42}$. Entretanto, a alta polaridade dos dois grupos carboxílicos resultou em baixa absorção oral $(<10 \%)^{43}$, o que implicava em uso apenas por via injetável. Isto representava, naturalmente, um problema para adesão do paciente, uma vez que seriam exigidas injeções diárias durante o tratamento crônico da hipertensão. A conversão deste grupo carboxílico em seu derivado éster de etila resultou no enalapril (14), com melhor lipofilicidade em relação ao primeiro ${ }^{44,45}$, e permitiu sua conveniente administração oral, com absorção entre $60-70 \%{ }^{43}$. Vale destacar que, uma vez absorvido, o enalapril (14) é convertido ao seu ácido de origem, através da hidrólise da ligação éster, condição essencial para produção do efeito farmacológico.

Embora vários fármacos sejam eficientemente absorvidos a partir do trato gastrintestinal, muitos apresentam limitada biodisponibilidade sistêmica devida ao metabolismo pré-sistêmico (de primeira-passagem), ou a inativação antes de alcançar a circulação sistêmica ${ }^{17}$. Além de reduzir a dose que chega ao local de ação, o extenso metabolismo de primeira-passagem frequentemente resulta em significante variabilidade na biodisponibilidade, necessitando cuidadoso monitoramento dos níveis plasmáticos no paciente ${ }^{17}$.

Fármacos que apresentam hidroxilas fenólicas, especialmente, sofrem rápida inativação por conjugação - principalmente com sulfato, com ácido glicurônico ou por metilação - na parede intestinal e no fígado. Para impedir esta inativação e melhorar a biodisponibilidade oral, a estratégia habitual é mascarar o grupo metabolizável, isto é, converter o grupo fenólico a um pró-fármaco contendo um grupo éster ${ }^{17}$.

Exemplo desta estratégia foi o planejamento do pró-fármaco bambuterol (16), um derivado bis- $N, N$-dimetilcarbamato do broncodilatador terbutalina (17). A descoberta deste pró-fármaco foi motivada pela baixa biodisponibilidade oral da terbutalina (17), que sofre extenso metabolismo de primeira passagem $(70 \%)^{45}$. Os grupos transportadores $N, N$-dimetilcarbamato, introduzidos na molécula da terbutalina (17), além de serem bastante estáveis frente à hidrólise enzimática ou química, incorporavam ainda propriedades inibidoras de esterases, ou seja, eram capazes de reduzir sua própria taxa de metabolismo ${ }^{46}$. O resultado deste aumento da estabilidade metabólica foi um ganho na biodisponibilidade oral e na duração de ação.

Comparada com $5 \mathrm{mg}$ de terbutalina (17) tomada 3 vezes ao dia, uma dose única de $20 \mathrm{mg}$ por dia de bambuterol (16) fornece 
níveis plasmáticos mantidos de terbutalina (17) e um maior alívio sintomático da asma, com menor incidência de efeitos colaterais ${ }^{47}$. Grande parte da dose oral deste pró-fármaco alcança a circulação sanguínea na forma intacta, sem sofrer metabolismo pré-sistêmico, e concentra-se nos pulmões. A lenta liberação da terbutalina (17) a partir do metabolismo do bambuterol (16), sobretudo no próprio local de ação (tecido pulmonar), contribui grandemente para sua duração de ação de $24 \mathrm{~h}^{48}$, bem como para a redução dos efeitos colaterais, como tremores, graças aos menores e prolongados níveis plasmáticos da terbutalina (17) obtidos $^{46}$.

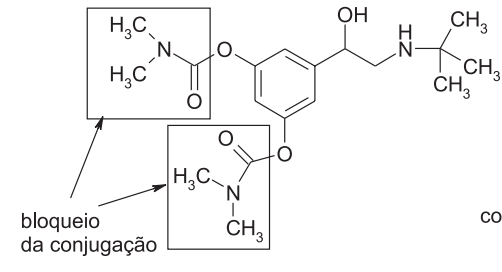

(16) bambuterol

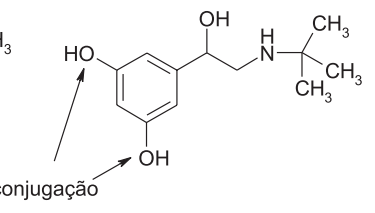

(17) terbutalina
Figura 6. Estruturas químicas dos broncodilatadores bambuterol (prófármaco) e terbutalina

\section{CONCLUSÃO}

O planejamento e otimização de uma molécula frente ao seu alvo terapêutico é apenas a ponta do "iceberg" na pesquisa de novos fármacos. Milhares de compostos são abandonados no longo caminho decorrido desde a concepção de uma nova molécula até sua comercialização, em grande parte devido à farmacocinética inadequada. Como o metabolismo, particularmente, é responsável por muitas destas propriedades indesejáveis - por ex., a presença de metabólitos ativos ou tóxicos, o extenso metabolismo présistêmico e a ampla variabilidade individual - a sua modulação, logo na fase pré-clínica, é de reconhecida importância para a seleção de compostos mais promissores. O desafio, naturalmente, é traçar modificações moleculares que resultem em um fármaco com múltiplas propriedades aceitáveis, sobretudo com eficácia terapêutica, segurança e facilidade de formulação, adequado para uso clínico. O objetivo desta breve revisão foi mostrar algumas das técnicas usadas para aperfeiçoar o metabolismo e, em última análise, a farmacocinética, destacando exemplos de estratégias bem sucedidas empregadas para solucionar estes problemas.

\section{GLOSSÁRIO}

Absorção - Em fisiologia e farmacologia, passagem de uma substância por difusão ou diálise através de uma membrana (como a mucosa intestinal $)^{49}$.

Agonista - É uma substância endógena ou uma droga que pode interagir com um receptor e iniciar uma resposta fisiológica ou farmacológica característica do receptor (contração, relaxamento, secreção, ativação enzimática, etc. $)^{50}$.

Alvo terapêutico - Sítio receptor eleito (enzima ou biorreceptor) com bases farmacológicas para ação de um fármaco ou protótipo capaz de permitir um determinado efeito terapêutico ${ }^{51}$.

Angina pectoris (Angina de peito) - Sensação de angústia, de opressão torácica, devido a um fornecimento insuficiente de oxigênio ao coração ${ }^{49}$.

Antagonista - É uma droga ou um composto que opõe os efeitos fisiológicos de outro composto. Em nível de receptor, é uma entidade química que opõe as respostas associadas à ativação do receptor, normalmente induzidas por outro agente bioativo ${ }^{50}$.
Arritmia cardíaca - Irregularidade do ritmo cardíaco percebida pelo pulso ou pela ausculta cardíaca ${ }^{49}$.

Biodisponibilidade - Termo que expressa a taxa ou concentração de fármaco que atinge a circulação sistêmica a partir do seu sítio de administração ${ }^{51}$.

$\mathbf{D}_{\mathbf{E}} \mathbf{5 0}$ - Dose do fármaco necessária para atingir 50\% do efeito farmacológico desejado ${ }^{51}$.

Depuração ("clearance") - Indica a taxa de remoção de uma substância do sangue quando ele atravessa um órgão, por ex., fígado ou $\operatorname{rim}^{52}$.

Impedimento estérico - Um efeito sobre as taxas de reações relativas causado quando o arranjo espacial de átomos ou grupos próximos ou nos sítios reativos impede ou retarda a reação ${ }^{53}$.

Indução enzimática - Processo pelo qual uma enzima (induzível) é sintetizada em resposta a uma molécula indutora específica ${ }^{50}$.

Infusão - Administração contínua de uma preparação fluida diluída de uma droga durante certo período (h ou dias), comumente por via intravenosa ${ }^{52}$.

Inibição enzimática - Diminuição ou supressão da atividade de uma enzima por uma determinada substância.

Hidrofóbico - Indica repulsão à água ${ }^{52}$.

Isósteros - São moléculas ou íons de tamanho similar contendo o mesmo número de átomos e elétrons de valência; ex. $\mathrm{O}^{2-}, \mathrm{F}^{-}$e $\mathrm{Ne}$ contém 8 elétrons de valência ${ }^{50}$.

Lipofilicidade - Representa a afinidade de uma molécula ou um grupamento por um ambiente lipofílico. É comumente medida por seu comportamento de distribuição em um sistema bifásico, ou líquido-líquido (ex., coeficiente de partição em octanol/água) ou sólido-líquido (ex., retenção em sistema cromatográfico de camada delgada $)^{50}$.

Metabolismo de primeira-passagem (ou eliminação présistêmica) - Este efeito se refere à possibilidade da droga, antes de cair na circulação sistêmica, sofrer, pelo menos parcialmente, ações metabólicas pelo epitélio intestinal e pelo fígado ${ }^{52}$.

Metabólito - É qualquer intermediário ou produto resultante do metabolismo ${ }^{50}$.

Potência - É a dose de uma droga requerida para produzir um efeito específico de dada intensidade, comparada a um padrão de referência ${ }^{50}$.

Receptor - É uma molécula ou uma estrutura polimérica dentro ou sobre uma célula que especificamente reconhece e se liga a um composto que atua como um mensageiro molecular (neurotransmissor, hormônio, linfocinas, lectinas, fármacos, etc. $)^{50}$.

Relação estrutura-atividade - É a relação entre estrutura química e atividade farmacológica para uma série de $\operatorname{compostos}^{50}$.

Seletividade - Capacidade de determinada concentração de droga em afetar uma única função biológica ${ }^{52}$.

Tempo de meia-vida - $\left(t_{1 / 2}\right)$ - É o tempo necessário para as concentrações plasmáticas ou a quantidade de fármaco no corpo serem reduzidas em $50 \%{ }^{54}$.

Variabilidade individual - Amplitude de variação das respostas às drogas, comumente expressas por uma curva de distribuição normal. A variação individual é, em grande parte, determinada geneticamente. Entretanto, hábitos pessoais, ambiente e outros fatores também influem ${ }^{52}$.

Xenobiótico - É um composto estranho ao organismo ${ }^{50}$.

\section{REFERÊNCIAS}

1. Ariëns, E. J.; Simonis, A. -M.; Top. Curr. Chem. 1974, 52, 1.

2. Abdel-Rahman, S.; Kauffman, R. E.; Annu. Rev. Pharmacol. Toxicol. 2004, $44,111$.

3. Smith, D. A.; Eur. J. Drug Metab. Pharmacokinet. 1994, 3, 193. 
4. Masimirembwa, C. M.; Bredberg, U.; Andersson, T. B.; Clin Pharmacokinet. 2003, 42, 515.

5. Prentis, R. A.; Lis, Y.; Walker, S. R.; Br. J. Clin. Pharmacol. 1988, 25, 387.

6. Smith, D. A.; Xenobiotica 1997, 27, 513; Lesko, L. J.; Rowland, M.; Peck, C. C.; Blaschke, T. F.; J. Clin. Pharmacol. 2000, 40, 803; Panchagnula, R.; Thomas, N. S.; Int. J. Pharm. 2000, 201, 131; Smith, D. A.; Xenobiotica 2001, 31, 459; Kerns, E. H.; Di, L.; Drug Discov. Today 2003, 8, 316; Walker, D. K.; Br. J. Clin. Pharmacol. 2004, 58, 601.

7. Chaikin, P.; Rhodes, G. R.; Bruno, R.; Rohatagi, S.; Natarajan, C.; J. Clin. Pharmacol. 2000, 40, 1428.

8. Korolkovas, A.; Burckhalter, J. H.; Química Farmacêutica, Ed. Guanabara: Rio de Janeiro, 1982, cap. 2.

9. Albert, A.; Nature 1958, 182, 421.

10. Barreiro, E. J.; Fraga, C. A. M.; Química Medicinal, Ed. Artmed: Porto Alegre, 2001, cap. 1

11. Low, L. K. Em Wilson and Gisvold's Textbook of Organic Medicinal and Pharmaceutical Chemistry; Delgado, J. N.; Remers, W. A., eds.; Lippincott Williams \& Wilkings: Philadelphia, 1998, cap. 3.

12. Lin, J. H.; Lu, A. Y. H.; Pharmacol. Rev. 1997, 49, 403.

13. http://www.currentdrugdiscovery.com, acessada em Junho 2005.

14. Nassar, A. F.; Kamel, A. M.; Clarimont, C.; Drug Discov. Today 2004, 9, 1020.

15. Testa, B. Em Burger's Medicinal Chemistry and Drug Discovery; Wolff, M. E., ed.; John Wiley \& Sons: New York, 1995, cap. 6.

16. van de Waterbeemd, H.; Smith, D. A.; Beaumont, K.; Walker, D. K.; J. Med. Chem. 2001, 44, 1313.

17. Bundgaard, H. Em Medicinal Chemistry for the $21^{\text {st }}$ Century; Wermuth, C. G.; Koga, N.; König, H., eds.; Blackwell Scientific Publications: Oxford, 1992, cap. 21.

18. Richardson, K.; Cooper, K.; Marriott, M. S.; Tarbit, M. H.; Troke, P. F.; Whittle, P. J.; Rev. Inf. Dis. 1990, 12, S267.

19. Humphrey, M. J.; Smith, D. A.; Xenobiotica 1992, 22, 743.

20. Lyman, C. A.; Sugar, A. M.; Diamond, R. D.; Antimicrob. Agents Chemother. 1986, 29, 161.

21. Smith, D. A.; Jones, B. C.; Walker, D. K.; Med. Res. Rev. 1996, 3, 243.

22. Bomont, H. L.; Tarbit, M. H.; Humphrey, M. J.; Houston, J. B.; Pharm. Res. 1994, 11, 951

23. Humphrey, M. J.; Drug Metab. Rev. 1996, 28, 473.

24. http://www.chemfinder.com, acessada em Junho 2005.

25. Manoury, P. M.; Binet, J. L.; Rousseau, J.; Lefevre-Borg, F.; Cavero, I. G.; J. Med. Chem. 1987, 30, 1003.

26. Riddell, J. G.; Harron, D. W.; Shanks, R. G.; Clin. Pharmacokinet. 1987, 12,305 .

27. Benfield, P.; Sorkin, E. M.; Drugs 1987, 33, 392.

28. Johnson, R. L. Em ref. 11, cap. 16.

29. Hoffman, B. B. Em Goodman \& Gilman As Bases Farmacológicas da Terapêutica; Hardman, J. G.; Limbird, L. E., eds.; $10^{\text {th }}$ ed., McGraw-Hill: Rio de Janeiro, 2003, cap. 10
30. Bodor, N.; Buchwald, P. Med. Res. Rev. 2000, 20, 58

31. Smith, F. T.; Clark, C. R. Em ref. 11, cap. 4.

32. Lin, J. H.; Lu, A. Y. H.; Pharmacol. Revs. 1997, 49, 403.

33. Kempf, D. J.; Marsch, K. C.; Fino, L. C.; Bryant, P.; Craig-Kennard, A.; Sham, H. L.; Zhao, C.; Vasavanonda, S.; Kohlbrenner, W. E.; Wideburg, N. E.; Saldivar, A.; Green, B. E.; Herrin, T.; Norbeck, D. W.; Bioorg. Med. Chem. 1994, 2, 847.

34. Kempf, D. J.; Sham, H. L.; Marsch, K. C.; Flentge, C. A.; Betebenner, D.; Brian, E. G.; McDonald, E.; Vasavanonda, S.; Saldivar, A.; Wideburg, N. E.; Kati, W. M.; Ruiz, L.; Zhao, C.; Fino, L.; Patterson, J.; Molla, A.; Plattner, J. J.; Norbeck, D. W.; J. Med. Chem. 1998, 41, 602.

35. Raffanti, S.; Haas, D. W. Em ref. 29, cap. 51

36. Clader, J. W.; J. Med. Chem. 2004, 47, 1.

37. http://www.shering-plough.com.br, acessada em Junho 2005.

38. Waller, D. G.; George, C. F.; Br. J. Clin. Pharmacol. 1989, 28, 497.

39. Bundgaard, H. Em Textbook of Drug Design and Development; Krogsgaard-Larsen, P.; Bundgaard, H., eds.; Hardwood: Chur, 1991, p. 113.

40. Chin, C. M.; Ferreira, E. I.; Quim. Nova 1999, 22, 75.

41. Ferreira, E. I.; Korolkovas, A.; Quim. Nova 1980, 3, 113; Stella, V. J.; Charman, W. N. A.; Naringrekar, V. H.; Drugs 1985, 29, 455; Bradley, D. A.; Adv. Drug Deliv. Rev. 1996, 19, 171; Beaumont, K.; Webster, R.; Gardner, I.; Dack, K.; Curr. Drug Metab. 2003, 4, 461; Testa, B.; Biochem. Pharmacol. 2004, 68, 2097; Ettmayer, P.; Gordon, L. A.; Clement, B.; Testa, B.; J. Med. Chem. 2004, 47, 2393. Wermuth, C. G. Em The Practice of Medicinal Chemistry; Wermuth, C. G., ed.; Academic: Amsterdam, 2003, cap. 33.

42. Patchett, A. A.; Br. J. Clin. Pharmacol. 1984, 18, 201S

43. Kubo, S. H.; Cody, R. J.; Clin. Pharmacokinet. 1985, 10, 377.

44. Ranadive, S. A.; Chen, A. X.; Serajuddin, A. T. M.; Pharm. Res. 1992, 9 , 1480; Dados de log P obtidos de: http//www.chemfinder.com, acessada em Julho 2005.

45. Tegner, K.; Nilsson, H. T.; Persson, C. G.; Persson, K.; Ryrfeldt, A.; Eur. Respir. Dis. Suppl. 1984, 134, 93.

46. Svensson, L. A.; Tunek, A.; Drug Metab. Rev. 1988, 19, 165.

47. Persson, G.; Pahlm, O.; Gnosspelius, Y.; Curr. Therap. Res. 1995, 56, 457.

48. Svensson, L. A.; Agents Actions Suppl. 1991, 34, 71.

49. Manuila, L.; Manuila, A.; Nicoulin, M.; Dicionário Andrei, $7^{\mathrm{a}}$ ed., Andrei: São Paulo, 1997.

50. Wermuth, C. G.; Ganellin, C. R.; Lindberg, P.; Mitscher, L. A.; Pure Appl. Chem. 1988, 70, 1129.

51. Barreiro, E. J.; Fraga, C. A. M.; Química Medicinal; Editora Artmed: Porto Alegre, 2001.

52. Penildon, S. Em Farmacologia; Penildon, S., ed.; $6^{\mathrm{a}}$ ed., Guanabara Koogan: Rio de Janeiro, 2002, cap. 2.

53. Solomons, G.; Fryhle, C.; Organic Chemistry, $7^{\text {th }}$ ed., Wiley: New York, 1998.

54. Hardman, J. G.; Limbird, L. E.; Gilman, A. G. Em ref. 29, cap. 1. 